\title{
Racial Differences in Medication Adherence: A Cross-Sectional Study of Medicare Enrollees
}

\author{
Ben S. Gerber, MD, MPH ${ }^{1,2}$, Young Ik Cho, $\mathrm{PhD}^{3}$, Ahsan M. Arozullah, MD, $\mathrm{MPH}^{2,}{ }^{*}$, and \\ Shoou-Yih D. Lee, $\mathrm{PhD}^{4}$ \\ ${ }^{1}$ Center for Management of Complex Chronic Care, Jesse Brown Veterans Affairs Medical \\ Center, Chicago, Illinois \\ ${ }^{2}$ Department of Medicine, University of Illinois at Chicago, Chicago, Illinois \\ ${ }^{3}$ Survey Research Laboratory and Center for Population Health and Health Disparities, University \\ of Illinois at Chicago, Chicago, Illinois \\ ${ }^{4}$ Department of Health Policy and Management, University of North Carolina at Chapel Hill, \\ Chapel Hill, North Carolina
}

\begin{abstract}
Background-Racial differences in adherence to prescribed medication regimens have been reported among the elderly. It remains unclear, however, whether these differences persist after controlling for confounding variables.
\end{abstract}

Objective-The objective of this study was to determine whether racial differences in medication adherence between African American and white seniors persist after adjusting for demographic characteristics, health literacy, depression, and social support. We hypothesized that differences in adherence between the 2 races would be eliminated after adjusting for confounding variables.

Methods-A survey on medication adherence was conducted using face-to-face interviews with Medicare recipients $\ 65$ years of age living in Chicago. Participants had to have good hearing and vision and be able to speak English to enable them to respond to questions in the survey and sign the informed-consent form. Medication adherence measures included questions about: (1) running out of medications before refilling the prescriptions; (2) following physician instructions on how to take medications; and (3) forgetting to take medications. Individual crude odds ratios (CORs) were calculated for the association between race and medication adherence. Adjusted odds ratios (AORs) were calculated using the following covariates in multivariate logistic regression analyses: race; age; sex; living with a spouse, partner, or significant other; income; Medicaid benefits; prescription drug coverage; having a primary care physician; history of hypertension or diabetes; health status; health literacy; depression; and social support.

(C) 2013 Excerpta Medica, Inc. All rights reserved.

Address correspondence to: Ben S. Gerber, MD, MPH, Institute for Health Research and Policy (M/C 275), 1747 West Roosevelt Road, Chicago, IL 60608. bgerber@uic.edu.

Current affiliation: Astellas Pharma Global Development, Inc., Deerfield, Illinois.

Astellas Pharma Global Development, Inc. (Dr. Arozullah's current employer) has no financial or editorial relationship with this manuscript. The authors have indicated that they have no other conflicts of interest regarding the content of this article.

Publisher's Disclaimer: This is a PDF file of an unedited manuscript that has been accepted for publication. As a service to our customers we are providing this early version of the manuscript. The manuscript will undergo copyediting, typesetting, and review of the resulting proof before it is published in its final citable form. Please note that during the production process errors may be discovered which could affect the content, and all legal disclaimers that apply to the journal pertain. 
Results-Six hundred thirty-three eligible cases were identified. Of the 489 patients who responded to the survey, 450 (266 African American [59\%; mean age, 78.2 years] and 184 white [41\%; mean age, 76.8 years]; predominantly women) were included in the sample. The overall response rate for the survey was $77.3 \%$. African Americans were more likely than whites to report running out of medications before refilling them $(\mathrm{COR}=3.01 ; 95 \% \mathrm{CI}, 1.72-5.28)$ and not always following physician instructions on how to take medications ( $\mathrm{COR}=2.64$; 95\% CI, 1.50-4.64). However, no significant difference between the races was observed in forgetting to take medications ( $\mathrm{COR}=0.90 ; 95 \% \mathrm{CI}, 0.61-1.31$ ). In adjusted analyses, race was no longer associated with low adherence due to refilling ( $\mathrm{AOR}=1.60 ; 95 \% \mathrm{CI}, 0.74-3.42)$. However, race remained associated with not following physician instructions on how to take medications after adjusting for confounding variables $(\mathrm{AOR}=2.49 ; 95 \% \mathrm{CI}, 1.07-5.80)$.

Conclusion-Elderly African Americans reported that they followed physician instructions on how to take medications less frequently than did elderly whites, even after adjusting for differences in demographic characteristics, health literacy, depression, and social support.

\section{Keywords}

medication adherence; African American; health disparities; aged

\section{INTRODUCTION}

Low adherence to prescribed medication regimens is common and associated with increases in morbidity, mortality, and health care costs. ${ }^{1-6}$ This is a particularly important concern among the elderly, many of whom have multiple chronic conditions that require complex medication regimens. ${ }^{4,7}$ In addition, older individuals may have greater difficulty in following prescription instructions due to age-related cognitive changes, declining memory, and impaired vision. ${ }^{8,9}$ Complex medical therapy, coupled with limited support in addressing these barriers to accessing and taking medications, increases the risks of low adherence and consequent hospitalization. ${ }^{4,10}$

Among the elderly, adherence to prescribed medication regimens has been reported to be lower among African Americans than among whites. ${ }^{11-19}$ A cross-sectional survey ${ }^{12}$ reported that African Americans were more likely to report cost-related low adherence than were whites (35.1\% vs $26.7 \%$ ). In another investigation, ${ }^{11}$ elderly African Americans were more likely to have cost-related low adherence than were whites even after adjusting for demographic characteristics, including income and prescription drug coverage.

Factors other than cost also may affect medication adherence and potentially contribute to racial differences. For example, some studies ${ }^{8,20}$ suggest that low health literacy is associated with low medication adherence, including refill adherence. One study ${ }^{21}$ suggested that health literacy may mediate the relationship between African American race and adherence to therapy for HIV. Depression, which is prevalent among the elderly, has been associated with low medication adherence, especially for those with chronic diseases. ${ }^{22-26}$ Milder symptoms of depression without a formal diagnosis of major depression may also be associated with low adherence in self-management of chronic diseases such as diabetes. ${ }^{27}$ African Americans may be less likely to be diagnosed and treated for depression in the primary care setting, contributing to racial differences in medication adherence. ${ }^{28}$ In contrast, strong social support may improve adherence and potentially attenuate the effect of health literacy and depression on medication adherence. ${ }^{9,29,30}$ Varied levels of social support could affect racial differences, where older African Americans may utilize informal social networks more often than whites. ${ }^{31,32}$ To further assess predictors of medication adherence and differences by race, these factors should be concomitantly evaluated and included in adherence models. 
It remains unclear whether racial differences in medication adherence behaviors exist after adjustment for these important confounders. Racial differences in medication adherence warrant further study because poor adherence may directly contribute to differences in chronic disease management, cardiovascular events, and mortality. ${ }^{33,34}$ In the Veterans Affairs health care system, racial differences exist for medication adherence despite equal access and cost; more detailed individual data are needed to explore the causes of these differences. 35

In the present study, cross-sectional data were obtained through face-to-face interviews with Medicare beneficiaries $\ 65$ years of age living in Chicago, Illinois, to determine whether racial differences in medication adherence between African Americans and whites persist after adjusting for demographic characteristics, health literacy, depression, and social support. We hypothesized that differences in adherence between African American and white seniors would be eliminated after this adjustment.

\section{METHODS \\ Data Collection}

Medicare recipients $\nsucceq 65$ years of age completed face-to-face interviews in their homes or at their participating medical center between March 2003 and February 2004 (before implementation of Medicare Part D). These patients participated in a study to explore the relationship between health literacy, health status, and health service utilization. ${ }^{29}$ Participants with $\geq 1$ out-patient clinic visit at the Mercy Hospital and Medical Center (MHMC) or the Mercy Family Health Center, both located in Chicago, within the previous 4 years (1999-2003) were recruited. Institutional review boards at the University of Illinois at Chicago, MHMC, and the University of North Carolina at Chapel Hill approved this study.

Potential respondents were screened by telephone for eligibility and willingness to participate. Participants had to be currently living in Illinois, have good vision (determined by vision questions during telephone screening and ability to see well enough during signing of the consent form) and good hearing (determined by responses to the screener without the use of a text telephone), and be able to conduct the interview in English. Participants were screened for cognitive impairment by requesting individuals to identify the state, year, and day of the week (minimum 2 out of 3 correct answers required for participation). In addition, the Mini-Mental State Examination (MMSE) ${ }^{36}$ was administered. The MMSE was included in our models and health literacy was left in the model without the MMSE due to colinearity.

After training at the Survey Research Laboratory at the University of Illinois at Chicago, interviews were conducted with eligible participants at a location chosen by the participant (eg, home, clinic) using a computer-assisted interviewing system. The interview assessed the respondent's sociodemographic characteristics, health literacy, social support, mental health status, medical comorbidities, and medication adherence.

\section{Measurement of Outcome Variables}

Medication adherence was assessed using questions based on the Hill-Bone Compliance to High Blood Pressure Therapy Scale (medication-taking behavior subscale) and recommended nonjudgmental interview approaches. ${ }^{37-39}$ Previous use of the Hill-Bone compliance scale included African American ${ }^{37}$ and white ${ }^{40}$ populations. One study ${ }^{40}$ of community-dwelling, elderly patients with hypertension found good reliability of the 9-item medication compliance survey (Cronbach $a=0.68$ ). The 3 items selected reflect how frequently patients followed specific behaviors related to overall medication adherence, without reference to specific types of medications. The questions included: 
1. Refilling Medication: "How often do you run out of your medications before you refill them?" Adherence was defined as "none of the time."

2. Following Instructions: "How often do you follow the physician's instructions on how to take your medications?" Adherence was defined as "all of the time."

3. Forgetting Medication: "How often have you forgotten to take your medicine?" Adherence was defined as "none of the time."

Possible responses were "all of the time," "most of the time," "some of the time," "a little of the time," or "none of the time." Cutoff levels to define adherence were based on skewed distributions of item results.

\section{Measurement of Other Variables}

Health literacy was measured using the Short Test of Functional Health Literacy in Adults. ${ }^{41}$ Test scores were classified into 2 health literacy categories: inadequate $(0-22$, subject is unable to read and interpret health texts or has difficulty doing so) and adequate (23-36, subject can read and interpret most health texts). Depression was measured using the 15item short form of the Geriatric Depression Scale $(\text { Cronbach } \alpha=0.806)^{42,43}$; scores were classified into the following categories: normal (0-4), mild depression (5-9), and moderate to severe depression (10-15). Social support was measured through the perceived social support scale developed in the Medical Outcomes Study, ${ }^{44}$ which assesses emotional, informational, tangible, positive social interaction, and affectionate support (Cronbach $a=$ 0.869). We also asked whether participants lived with someone (ie, a spouse, partner, or significant other).

Participants were asked about their annual income level (ie, including income from all sources and from all members of the household). Participants were asked whether they received Medicaid benefits and whether they had prescription drug coverage through either their health insurance or a special government program. To evaluate access to a primary care physician, participants were asked whether they had one main person they thought of as their personal doctor or health care provider. To determine whether participants had a history of hypertension or diabetes, they were asked whether they had ever been told by a doctor, nurse, or other health care professional that they had one of these conditions. An item self-rated on a 5-point Likert scale (excellent, very good, good, fair, or poor; coded 15 , respectively) was used to assess health status. This single-item assessment of global health status is a valid, reliable, and useful measure of an individual's well-being. ${ }^{45,46} \mathrm{~A}$ similar item can be found in the Short Form Health Survey as well as the National Health Interview Survey, National Health and Nutrition Examination Survey, and Behavioral Risk Factor Surveillance System national instruments. ${ }^{46,47}$ Reponses to this item are highly correlated with many health outcomes and mortality. ${ }^{46}$ Also included in the analysis were the respondent's age and sex.

\section{Statistical Analysis}

To assess differences in characteristics between the African American and white participants, standard 2-tailed $t$ tests were performed for continuous variables and $\chi^{2}$ tests for categorical variables. Results were examined to determine whether racial differences existed in medication adherence outcomes. Individual crude odds ratios (CORs) were calculated for the association between race (African American vs white) and medication adherence (refilling medications, following physician instructions, and forgetting medications). Multivariate logistic regression analyses were used to calculate adjusted odds ratios (AORs) for the 3 adherence outcomes, using the following covariates: race; age; sex; living with a spouse, partner, or significant other; income; Medicaid benefits; prescription drug coverage; having a primary care physician; history of hypertension or diabetes; health 
status; health literacy; depression; and social support. According to the framework developed by Murray et al, ${ }^{9}$ these covariates represented important personal characteristics that may explain medication adherence. All ORs were reported with 95\% CIs, with significance defined as $P<0.05$. All analyses were conducted using SPSS for Windows version 16.0 (SPSS Inc., Chicago, Illinois).

\section{RESULTS}

\section{Description of the Study Sample}

Six hundred thirty-three eligible cases were identified; 489 patients responded to the survey (overall response rate, $77.3 \%$ ). The sample included 450 participants 66 to 103 years of age (266 [59\%] African American and 184 [41\%] white; self-identified) (Table I); the ethnic groups for the remaining 39 patients were small in number and diverse. The 2 primary racial groups were similar in terms of sex: $78.2 \%$ of African American participants and $79.3 \%$ of white participants were women $(P=0.77)$. In addition, a majority of both racial groups reported having prescription drug coverage (72.5\% of African Americans vs $73.8 \%$ of whites; $P=0.77)$. However, compared with white participants, African American participants were older (mean age, 78.2 vs 76.8 years; $P=0.026$ ), had less income $(P<$ 0.001 ), and had received greater Medicaid benefits (53.6\% vs $21.3 \% ; P<0.001)$. Fewer African Americans reported living with a spouse, partner, or significant other (19.2\% vs $28.3 \% ; P=0.024)$ or having a primary care physician $(84.2 \%$ vs $96.2 \% ; P<0.001)$. More African Americans reported having a history of hypertension $(70.7 \%$ vs $57.1 \% ; P=0.003$ ) or diabetes $(26.3 \%$ vs $14.7 \% ; P=0.003)$, as well as worse health status, lower health literacy, worse depression scores, and less social support than did white participants (all, $P<$ $0.001)$.

\section{Unadjusted Medication Adherence Outcomes}

Participants in the 2 racial groups reported significantly different responses to 2 of the 3 medication adherence questions (Table II). Whites were more likely than African Americans to report never running out of medications before refilling them $(90.2 \%$ vs $75.3 \%$; COR $=$ $3.01 ; 95 \% \mathrm{CI}, 1.72-5.28)$ and more likely to follow physician instructions on how to take medications ( $90.1 \%$ vs $77.6 \%$; COR $=2.64$; $95 \%$ CI, $1.50-4.64)$. However, no significant between-race difference was observed in participants forgetting to take their medications (47.8\% of whites vs $50.6 \%$ of African Americans; COR $=0.90 ; 95 \%$ CI, $0.61-1.31$ ).

\section{Multivariate Analyses}

Multivariate logistic regression was performed to evaluate the 3 medication adherence items (running out of medications, not following physician instructions, and forgetting medications) (Table III). After controlling for variables (age; sex; living with a spouse, partner, or significant other; income; Medicaid benefits; prescription drug coverage; having a primary care physician; history of hypertension or diabetes; health status; health literacy; depression; and social support), race was no longer associated with low adherence due to refilling ( $\mathrm{AOR}=1.60 ; 95 \% \mathrm{CI}, 0.74-3.42)$. In addition, none of the covariates was statistically significant at the $P<0.05$ level. However, African Americans were more likely than whites to not always follow physician instructions on how to take medications (AOR = $2.49 ; 95 \% \mathrm{CI}, 1.07-5.80)$ after controlling for the same variables. In contrast, a history of hypertension $(\mathrm{AOR}=0.38 ; 95 \% \mathrm{CI}, 0.20-0.71)$ and social support $(\mathrm{AOR}=0.51 ; 95 \% \mathrm{CI}$, $0.35-0.76$ ) were associated with following physician instructions on how to take medications. In the multivariate model of forgetting medications, income (2003-2004 US \$) of $\$ 20,000$ to $\$ 24,999$ ( $\mathrm{AOR}=0.45 ; 95 \% \mathrm{CI}, 0.22-0.93$ ), $\$ 10,000$ to $\$ 14,999$ ( $\mathrm{AOR}=0.39$; $95 \% \mathrm{CI}, 0.18-0.84$ ), and $<\$ 10,000$ ( $\mathrm{AOR}=0.34 ; 95 \% \mathrm{CI}, 0.14-0.83$ ), and social support (AOR $=0.60 ; 95 \% \mathrm{CI}, 0.44-0.81)$ were significant. 


\section{DISCUSSION}

In this sample of Medicare enrollees, a significant difference in self-reported medication adherence-following physician instructions on how to take medications-was found between African American and white participants. This discrepancy persisted after adjusting for confounding variables. Although African American participants had significantly lower health literacy, depression scores, and social support than did whites, race remained an important factor in the multivariate model.

The difference in following physician instructions on how to take medications is consistent with other studies that reported lower rates of medication adherence among African American populations than among white populations. ${ }^{10-18}$ This form of medication adherence represents intentional adherence, which typically involves a decision-making process (weighing the costs and benefits of taking medication). ${ }^{48,49}$ This may also reflect differences in knowledge, attitudes, or lay health beliefs that influence medication decisions, resulting in skipping or altering doses. In one study of low-income persons with diabetes, ${ }^{50}$ African Americans were found to be more concerned about medication harmfulness than were whites, independent of income, medication cost, and health literacy. This concern for harm was associated with medication underuse and worse blood pressure control. African Americans may also express greater concern for medication adverse effects and dependency than their white counterparts, as well as greater reluctance to adding medication to their regimens. ${ }^{51}$ Differences in patient-provider relationships (eg, patient-physician communication concerning prescriptions, trust) may further contribute to the discrepancy in adherence. ${ }^{52,53}$ Together, these concerns may affect individual decisions pertaining to following physician instructions on how to take medications and potentially explain racial differences in intentional adherence. In contrast, no significant differences in running out of medications before refilling or forgetting to take medications were observed between African American and white participants in the full, adjusted models. It is possible that these 2 types of medication adherence rely less on individual attitudes and beliefs. ${ }^{49}$

Social support was associated with both following physician instructions on how to take medications and forgetting to take medications. Other studies have found similar associations between perceived social support and adherence. ${ }^{4,54,55}$ The involvement of others (eg, family members, neighbors) in providing knowledge and reminders may help to overcome barriers to long-term medication adherence, especially when support efforts are tailored to an individual's specific needs. ${ }^{56}$ This is particularly relevant for the elderly who live alone and have cognitive impairment or disability. Greater use of informal social networks by African American seniors may improve medication adherence, but likely would not eliminate the impact of race on adherence.

No significant differences in forgetting to take medications were found between African American and white seniors. This form of unintentional nonadherence is common; 50\% of the sample reported forgetting to take their medications. Other studies have also found relatively high rates of various forms of low medication adherence among seniors. For example, in a 2003 national survey of Medicare beneficiaries aged $\ 65$ years, $40 \%$ of the sample reported some form of medication nonadherence during the past year. ${ }^{57}$ Low adherence rates were reported more frequently for those with complex chronic conditions, low income, and no prescription drug coverage (range, 48\%-52\%).

Previous research suggests that forgetfulness is a common cause of poor medication adherence; this includes retrospective memory failure (forgetting what they have been told about medications and whether they took their medications) and prospective memory failure (forgetting to take their medications). ${ }^{9,58}$ Because of the high degree of forgetfulness 
described by seniors overall ( $\sim 50 \%$ of the sample), interventions are needed to specifically address this problem. Examples of interventions include cueing, chaining (associating new and established behaviors), use of social support or ancillary clinical services (eg, family members, nurses, pharmacists), and electronic monitoring devices. ${ }^{1}$ Providers can help by simplifying seniors' complex medical regimens (eg, using once-daily dosing when possible) and discontinuing unnecessary medications.

The major strength of this study is the inclusion of individualized assessments of health literacy, depression, and social support among a cohort of Medicare enrollees who resided in similar neighborhoods and were treated at the same medical facility. Thus, our results were not confounded by geographic or organizational variations that may affect health care delivery and patient adherence. However, a number of limitations must be acknowledged. First, we utilized only self-reported adherence questions as outcomes. Other detailed surveys that evaluate cost-related low adherence or alternative measures of adherence (eg, pill counts, medication event monitoring systems) may improve adherence assessments. Second, participants may have overestimated their levels of adherence to provide more desirable responses during interviews. Third, participants indicated their overall adherence to medication regimens, although the number, type, and complexity of the medications prescribed likely vary widely. In this sample, adjustments for comorbid conditions (ie, hypertension and diabetes) and health status did not significantly alter our results. Adjustments were not made for other chronic conditions (eg, congestive heart failure, coronary artery disease, chronic obstructive pulmonary disease) or disease prognosis. Fourth, although cost-related nonadherence is a well-recognized problem, we were unable to adjust for cost of medication. Fifth, the study sample came from an inner-city neighborhood of a metropolitan area, which may have limited the generalizability of the findings. Finally, the cross-sectional design precluded the determination of causality.

The finding of racial differences in medication adherence has important implications because lower adherence can contribute to significant racial disparities in chronic disease outcomes. The objective of reducing health disparities requires further investigation in underlying differences that explain medication-related behaviors. We need better policies and well-designed interventions to help those individuals who are most vulnerableminority seniors with low income levels and poor social support. Health care providers should adopt a culturally sensitive, patient-centered approach to identifying and addressing barriers to adherence. Improvements made in medication adherence may translate into better management of chronic diseases and reduced disparities in cardiovascular and other diseases that rely on complex medical therapy.

\section{CONCLUSIONS}

Racial differences exist in how seniors report taking medications. More African Americans than whites reported not following their physician's instructions on how to take medications. The racial differences persisted after adjusting for demographic characteristics, including income, prescription drug coverage, health literacy, depression, and social support.

\section{Acknowledgments}

This study was supported by grants from the Agency for Healthcare Research and Quality (R01 HS13004) and the National Cancer Institute (P50 CA106743). The authors wish to acknowledge Meredith Chapman and Alexander Sokolovsky for their efforts in manuscript preparation.

The views expressed in this article are those of the authors and do not necessarily reflect the position or policy of the Department of Veterans Affairs or the United States government. 


\section{References}

1. Bosworth, HB.; Oddone, EZ.; Weinberger, M., editors. Patient Treatment Adherence: Concepts, Interventions, and Measurement. Mahwah, NJ: Lawrence Erlbaum Associates, Publishers; 2006.

2. Osterberg L, Blaschke T. Adherence to medication. N Engl J Med. 2005; 353:487-497. [PubMed: 16079372]

3. Sokol MC, McGuigan KA, Verbrugge RR, Epstein RS. Impact of medication adherence on hospitalization risk and healthcare cost. Med Care. 2005; 43:521-530. [PubMed: 15908846]

4. Col N, Fanale JE, Kronholm P. The role of medication noncompliance and adverse drug reactions in hospitalizations of the elderly. Arch Intern Med. 1990; 150:841-845. [PubMed: 2327844]

5. Hanlon JT, Lindblad CI, Hajjar ER, McCarthy TC. Update on drug-related problems in the elderly. Am J Geriatr Pharmacother. 2003; 1:38-43. [PubMed: 15555464]

6. Morisky DE, Green LW, Levine DM. Concurrent and predictive validity of a self-reported measure of medication adherence. Med Care. 1986; 24:67-74. [PubMed: 3945130]

7. Murray MD, Callahan CM. Improving medication use for older adults: An integrated research agenda. Ann Intern Med. 2003; 139:425-429. [PubMed: 12965970]

8. Gazmararian JA, Kripalani S, Miller MJ, et al. Factors associated with medication refill adherence in cardiovascular-related diseases: A focus on health literacy. J Gen Intern Med. 2006; 21:12151221. [PubMed: 17105519]

9. Murray MD, Morrow DG, Weiner M, et al. A conceptual framework to study medication adherence in older adults. Am J Geriatr Pharmacother. 2004; 2:36-43. [PubMed: 15555477]

10. van Eijken M, Tsang S, Wensing M, et al. Interventions to improve medication compliance in older patients living in the community: A systematic review of the literature. Drugs Aging. 2003; 20:229-240. [PubMed: 12578402]

11. Soumerai SB, Pierre-Jacques M, Zhang F, et al. Cost-related Medication nonadherence among elderly and disabled Medicare beneficiaries: A national survey 1 year before the Medicare drug benefit. Arch Intern Med. 2006; 166:1829-1835. [PubMed: 17000938]

12. Gellad WF, Haas JS, Safran DG. Race/ethnicity and nonadherence to prescription medications among seniors: Results of a national study. J Gen Intern Med. 2007; 22:1572-1578. [PubMed: 17882499]

13. Monane M, Bohn RL, Gurwitz JH, et al. Compliance with antihypertensive therapy among elderly Medicaid enrollees: The roles of age, gender, and race. Am J Public Health. 1996; 86:1805-1808. [PubMed: 9003143]

14. Roth MT, Ivey JL. Self-reported medication use in community-residing older adults: A pilot study. Am J Geriatr Pharmacother. 2005; 3:196-204. [PubMed: 16257822]

15. Sharkness CM, Snow DA. The patient's view of hypertension and compliance. Am J Prev Med. 1992; 8:141-146. [PubMed: 1632999]

16. Bosworth HB, Powers B, Grubber JM, et al. Racial differences in blood pressure control: Potential explanatory factors. J Gen Intern Med. 2008; 23:692-698. [PubMed: 18288540]

17. Clark LT, Maki KC, Galant R, et al. Ethnic differences in achievement of cholesterol treatment goals. Results from the National Cholesterol Education Program Evaluation Project Utilizing Novel E-Technology II. J Gen Intern Med. 2006; 21:320-326. [PubMed: 16686806]

18. Kaplan RC, Bhalodkar NC, Brown EJ Jr, et al. Race, ethnicity, and sociocultural characteristics predict non-compliance with lipid-lowering medications. Prev Med. 2004; 39:1249-1255. [PubMed: 15539064]

19. Sleath B, Ballinger R, Covert D, et al. Self-reported prevalence and factors associated with nonadherence with glaucoma medications in veteran outpatients. Am J Geriatr Pharmacother. 2009; 7:67-73. [PubMed: 19447359]

20. Keller DL, Wright J, Pace HA. Impact of health literacy on health outcomes in ambulatory care patients: A systematic review. Ann Pharmacother. 2008; 42:1272-1281. [PubMed: 18648014]

21. Osborn CY, Paasche-Orlow MK, Davis TC, Wolf MS. Health literacy: An overlooked factor in understanding HIV health disparities. Am J Prev Med. 2007; 33:374-378. [PubMed: 17950402]

22. Benner JS, Glynn RJ, Mogun H, et al. Long-term persistence in use of statin therapy in elderly patients. JAMA. 2002; 288:455-461. [PubMed: 12132975] 
23. Carney RM, Freedland KE, Eisen SA, et al. Major depression and medication adherence in elderly patients with coronary artery disease. Health Psychol. 1995; 14:88-90. [PubMed: 7737079]

24. DiMatteo MR, Lepper HS, Croghan TW. Depression is a risk factor for noncompliance with medical treatment: Meta-analysis of the effects of anxiety and depression on patient adherence. Arch Intern Med. 2000; 160:2101-2107. [PubMed: 10904452]

25. Gehi A, Haas D, Pipkin S, Whooley MA. Depression and medication adherence in outpatients with coronary heart disease: Findings from the Heart and Soul Study. Arch Intern Med. 2005; 165:2508-2513. [PubMed: 16314548]

26. Wang PS, Bohn RL, Knight E, et al. Noncompliance with antihypertensive medications: The impact of depressive symptoms and psychosocial factors. J Gen Intern Med. 2002; 17:504-511. [PubMed: 12133140]

27. Gonzalez JS, Safren SA, Cagliero E, et al. Depression, self-care, and medication adherence in type 2 diabetes: Relationships across the full range of symptom severity. Diabetes Care. 2007; 30:2222-2227. [PubMed: 17536067]

28. Stockdale SE, Lagomasino IT, Siddique J, et al. Racial and ethnic disparities in detection and treatment of depression and anxiety among psychiatric and primary health care visits, 1995-2005. Med Care. 2008; 46:668-677. [PubMed: 18580385]

29. Cho YI, Lee SY, Arozullah AM, Crittenden KS. Effects of health literacy on health status and health service utilization amongst the elderly. Soc Sci Med. 2008; 66:1809-1816. [PubMed: 18295949]

30. Lee SY, Arozullah AM, Cho YI. Health literacy, social support, and health: A research agenda. Soc Sci Med. 2004; 58:1309-1321. [PubMed: 14759678]

31. Chadiha LA, Proctor EK, Morrow-Howell N, et al. Post-hospital home care for African American and white elderly. Gerontologist. 1995; 35:233-239. [PubMed: 7750780]

32. Ford ME, Tilley BC, McDonald PE. Social support among African American adults with diabetes, Part 2: A review. J Natl Med Assoc. 1998; 90:425-432. [PubMed: 9685778]

33. Heisler M, Faul JD, Hayward RA, et al. Mechanisms for racial and ethnic disparities in glycemic control in middle-aged and older Americans in the health and retirement study. Arch Intern Med. 2007; 167:1853-1860. [PubMed: 17893306]

34. Davis AM, Vinci LM, Okwuosa TM, et al. Cardiovascular health disparities: A systematic review of health care interventions. Med Care Res Rev. 2007; 64(Suppl 5):29S-100S. [PubMed: 17881625]

35. Saha S, Freeman M, Toure J, et al. Racial and ethnic disparities in the VA health care system: A systematic review. J Gen Intern Med. 2008; 23:654-671. [PubMed: 18301951]

36. Folstein MF, Folstein SE, McHugh PR. "Mini-mental state": A practical method for grading the cognitive state of patients for the clinician. J Psychiatr Res. 1975; 12:189-198. [PubMed: 1202204]

37. Kim MT, Hill MN, Bone LR, Levine DM. Development and testing of the Hill-Bone Compliance to High Blood Pressure Therapy Scale. Prog Cardiovasc Nurs. 2000; 15:90-96. [PubMed: 10951950]

38. Eraker SA, Kirscht JP, Becker MH. Understanding and improving patient compliance. Ann Intern Med. 1984; 100:258-268. [PubMed: 6362512]

39. Yiannakopoulou, ECh; Papadopulos, JS.; Cokkinos, DV.; Mountokalakis, TD. Adherence to antihypertensive treatment: A critical factor for blood pressure control. Eur J Cardiovasc Prev Rehabil. 2005; 12:243-249. [PubMed: 15942423]

40. Krousel-Wood M, Muntner P, Jannu A, et al. Reliability of a medication adherence measure in an outpatient setting. Am J Med Sci. 2005; 330:128-133. [PubMed: 16174996]

41. Baker DW, Williams MV, Parker RM, et al. Development of a brief test to measure functional health literacy. Patient Educ Couns. 1999; 38:33-42. [PubMed: 14528569]

42. Sheikh JI, Yesavage JA, Brooks JO III, et al. Proposed factor structure of the Geriatric Depression Scale. Int Psychogeriatr. 1991; 3:23-28. [PubMed: 1863703]

43. Yesavage JA, Brink TL, Rose TL, et al. Development and validation of a geriatric depression screening scale: A preliminary report. J Psychiatr Res. 1982-1983; 17:37-49. [PubMed: 7183759] 
44. Sherbourne CD, Stewart AL. The MOS social support survey. Soc Sci Med. 1991; 32:705-714. [PubMed: 2035047]

45. Houston TK, Allison JJ. Users of internet health information: Differences by health status. J Med Internet Res. 2002; 4:e7. [PubMed: 12554554]

46. Fayers PM, Sprangers MA. Understanding self-rated health. Lancet. 2002; 359:187-188. [PubMed: 11812551]

47. Krause NM, Jay GM. What do global self-rated health items measure? Med Care. 1994; 32:930942. [PubMed: 8090045]

48. Lowry KP, Dudley TK, Oddone EZ, Bosworth HB. Intentional and unintentional nonadherence to antihypertensive medication. Ann Pharmacother. 2005; 39:1198-1203. [PubMed: 15956238]

49. Wroe AL. Intentional and unintentional nonadherence: A study of decision making. J Behav Med. 2002; 25:355-372. [PubMed: 12136497]

50. Aikens JE, Piette JD. Diabetic patients' medication underuse, illness outcomes, and beliefs about antihyperglycemic and antihypertensive treatments. Diabetes Care. 2009; 32:19-24. [PubMed: 18852334]

51. Huang ES, Brown SE, Thakur N, et al. Racial/ethnic differences in concerns about current and future medications among patients with type 2 diabetes. Diabetes Care. 2009; 32:311-316. [PubMed: 19017766]

52. Wilson IB, Schoen C, Neuman P, et al. Physician-patient communication about prescription medication non-adherence: A 50-state study of America's seniors. J Gen Intern Med. 2007; 22:612. [PubMed: 17351835]

53. Gaskin DJ, Briesacher BA, Limcangco R, Brigantti BL. Exploring racial and ethnic disparities in prescription drug spending and use among Medicare beneficiaries. Am J Geriatr Pharmacother. 2006; 4:96-111. [PubMed: 16860257]

54. Wu JR, Moser DK, Chung ML, Lennie TA. Predictors of medication adherence using a multidimensional adherence model in patients with heart failure. J Card Fail. 2008; 14:603-614. [PubMed: 18722327]

55. Schlenk EA, Dunbar-Jacob J, Engberg S. Medication non-adherence among older adults: A review of strategies and interventions for improvement. J Gerontol Nurs. 2004; 30:33-43. [PubMed: 15287325]

56. Touchette DR, Shapiro NL. Medication compliance, adherence, and persistence: Current status of behavioral and educational interventions to improve outcomes. J Manag Care Pharm. 2008; 14(Suppl S-d):S2-S10.

57. Safran DG, Neuman P, Schoen C, et al. Prescription drug coverage and seniors: Findings from a 2003 national survey. Health Aff (Millwood). 2005; (Suppl Web Exclusives):W5-W152-W5W166. [PubMed: 15840625]

58. Stoehr GP, Lu SY, Lavery L, et al. Factors associated with adherence to medication regimens in older primary care patients: The Steel Valley Seniors Survey. Am J Geriatr Pharmacother. 2008; 6:255-263. [PubMed: 19161928] 


\section{Table I}

Characteristics of the study sample $(\mathrm{N}=450)$. Data are $\%$ unless otherwise indicated.

\begin{tabular}{|c|c|c|c|}
\hline Characteristic & African American $(n=266)$ & White $(n=184)$ & $P$ \\
\hline Age, mean (SD) & $78.2(7.25)$ & $76.8(6.05)$ & 0.026 \\
\hline Sex, male & 21.8 & 20.7 & 0.77 \\
\hline Currently living with a spouse, partner, or significant other & 19.2 & 28.3 & 0.024 \\
\hline Income ${ }^{* \dagger}$ & & & $<0.001$ \\
\hline $2 \$ 25,000$ & 6.3 & 38.7 & \\
\hline$\$ 20,000-\$ 24,999$ & 11.1 & 28.2 & \\
\hline$\$ 15,000-\$ 19,999$ & 17.4 & 8.6 & \\
\hline$\$ 10,000-\$ 14,999$ & 31.2 & 16.0 & \\
\hline$<\$ 10,000$ & 34.0 & 8.6 & \\
\hline Medicaid $^{*}$ & 53.6 & 21.3 & $<0.001$ \\
\hline Prescription drug coverage ${ }^{*}$ & 72.5 & 73.8 & 0.77 \\
\hline Primary care physician & 84.2 & 96.2 & $<0.001$ \\
\hline Hypertension & 70.7 & 57.1 & 0.003 \\
\hline Diabetes & 26.3 & 14.7 & 0.003 \\
\hline Health status & & & $<0.001$ \\
\hline Poor & 18.0 & 7.1 & \\
\hline Fair & 44.7 & 20.1 & \\
\hline Good & 25.6 & 39.1 & \\
\hline Very good & 9.4 & 26.1 & \\
\hline Excellent & 2.3 & 7.6 & \\
\hline Health literacy, adequate & 26.7 & 81.5 & $<0.001$ \\
\hline Depression $^{\dagger}$ & & & $<0.001$ \\
\hline None & 62.0 & 82.6 & \\
\hline Mild & 33.8 & 14.1 & \\
\hline Severe & 4.1 & 3.3 & \\
\hline Social support, mean $(\mathrm{SD})^{*}$ & $3.70(0.96)$ & $4.30(0.70)$ & $<0.001$ \\
\hline
\end{tabular}




\section{Table II}

Responses and crude (unadjusted) odds ratios for medication adherence questions.

\begin{tabular}{|c|c|c|c|}
\hline \multirow[b]{2}{*}{ Question } & \multicolumn{2}{|c|}{ n/N (\%) of Participants } & \multirow[b]{2}{*}{$\begin{array}{l}\text { Crude Odds Ratio (95\% } \\
\text { CI) }\end{array}$} \\
\hline & $\underset{266)}{\operatorname{African} \text { American }(\mathrm{n}=}$ & White $(n=184)$ & \\
\hline $\begin{array}{l}\text { "How often do you run out of your medications before you } \\
\text { refill them?" Response: "None of the time."* }\end{array}$ & $198 / 263(75.3)$ & $165 / 183(90.2)$ & $3.01(1.72-5.28)$ \\
\hline $\begin{array}{l}\text { "How often do you follow the physician's instructions on how } \\
\text { to take your medications?" Response: "All of the time." }{ }^{\dagger}\end{array}$ & 204/263 (77.6) & $164 / 182(90.1)$ & $2.64(1.50-4.64)$ \\
\hline $\begin{array}{l}\text { "How often have you forgotten to take your medicine?" } \\
\text { Response: "None of the time." }{ }^{\dagger}\end{array}$ & $133 / 263(50.6)$ & 87/182 (47.8) & $0.90(0.61-1.31)$ \\
\hline
\end{tabular}




\section{Table III}

Multivariate logistic regression models for medication adherence questions.

\begin{tabular}{|c|c|c|c|}
\hline \multirow[b]{2}{*}{ Variable } & \multicolumn{3}{|c|}{ Adjusted Odds Ratio (95\% CI) } \\
\hline & $\begin{array}{l}\text { Running Out of Medication } \\
\text { Before Refilling }\end{array}$ & $\begin{array}{l}\text { Not Always Following } \\
\text { Physician Instructions on } \\
\text { How to Take Medication }\end{array}$ & $\begin{array}{l}\text { Forgetting to Take } \\
\text { Medication }\end{array}$ \\
\hline Race, African American (vs white) & $1.60(0.74-3.42)$ & $2.49(1.07-5.80)$ & $0.65(0.37-1.16)$ \\
\hline Age & $1.01(0.97-1.05)$ & $0.96(0.91-1.00)$ & $1.00(0.96-1.03)$ \\
\hline Sex, male & $0.62(0.29-1.32)$ & $0.97(0.45-2.09)$ & $0.86(0.48-1.53)$ \\
\hline $\begin{array}{l}\text { Currently living with a spouse, partner, or } \\
\text { significant other; yes }\end{array}$ & $1.07(0.50-2.32)$ & $0.66(0.28-1.58)$ & $1.03(0.58-1.83)$ \\
\hline Income, $\$ 25,000$ & Reference & Reference & Reference \\
\hline$\$ 20,000-\$ 24,999$ & $0.86(0.31-2.41)$ & $3.25(0.95-11.1)$ & $0.45(0.22-0.93)$ \\
\hline$\$ 15,000-\$ 19,999$ & $0.94(0.31-2.91)$ & $4.13(1.10-15.5)$ & $0.81(0.35-1.88)$ \\
\hline$\$ 10,000-\$ 14,999$ & $0.91(0.32-2.60)$ & $1.68(0.45-6.25)$ & $0.39(0.18-0.84)$ \\
\hline$<\$ 10,000$ & $0.66(0.21-2.14)$ & $2.27(0.58-8.98)$ & $0.34(0.14-0.83)$ \\
\hline Medicaid, yes & $0.74(0.40-1.35)$ & $0.70(0.36-1.37)$ & $1.11(0.68-1.82)$ \\
\hline Prescription drug coverage, yes & $1.09(0.58-2.05)$ & $1.23(0.60-2.53)$ & $1.07(0.65-1.75)$ \\
\hline Primary care physician, yes & $0.59(0.27-1.29)$ & $1.53(0.59-3.94)$ & $1.29(0.64-2.62)$ \\
\hline Hypertension, yes & $0.89(0.49-1.63)$ & $0.38(0.20-0.71)$ & $1.20(0.75-1.91)$ \\
\hline Diabetes, yes & $1.74(0.91-3.30)$ & $0.47(0.20-1.09)$ & $0.72(0.42-1.25)$ \\
\hline Health status, poor & Reference & Reference & Reference \\
\hline Fair & $0.90(0.39-2.08)$ & $0.73(0.29-1.84)$ & $1.14(0.54-2.40)$ \\
\hline Good & $0.64(0.25-1.64)$ & $0.44(0.15-1.28)$ & $1.18(0.53-2.64)$ \\
\hline Very good & $0.67(0.22-2.09)$ & $0.96(0.30-3.14)$ & $1.48(0.60-3.64)$ \\
\hline Excellent & $0.70(0.12-3.97)$ & $2.28(0.47-11.1)$ & $0.52(0.14-1.94)$ \\
\hline Health literacy, adequate & $0.66(0.33-1.33)$ & $0.86(0.41-1.84)$ & $0.72(0.41-1.26)$ \\
\hline Depression, none & Reference & Reference & Reference \\
\hline Mild & $1.42(0.72-2.81)$ & $0.63(0.28-1.42)$ & $1.24(0.70-2.21)$ \\
\hline Severe & $3.22(0.84-12.4)$ & $1.62(0.38-6.86)$ & $3.35(0.85-13.2)$ \\
\hline Social support & $0.89(0.63-1.27)$ & $0.51(0.35-0.76)$ & $0.60(0.44-0.81)$ \\
\hline
\end{tabular}

